\title{
Effectiveness and Efficiency of Different Doses of Physical Mutagen ( $\gamma$ - rays) in Clusterbean [Cyamopsis tetragonoloba (L.) Taub.] Genotypes
}

\author{
Jaya Rathore*, A.K. Singh and S.V.S. Chauhan \\ Department of Genetics and Plant Breeding, College of Agriculture, RVSKVV, Gwalior, India \\ *Corresponding author
}

\section{A B S T R A C T}

Keywords

Cluster bean,

Mutagen,

Mutagenic

effectiveness,

Mutagenic

efficiency, Mutation

frequency

\section{Article Info}

Accepted:

07 June 2019

Available Online:

10 July 2019
In the present investigation, the mutagenic effectiveness and efficiency of different doses of a physical mutagen (gamma rays) were studied in clusterbean (Cyamopsis tetragonoloba (L) Taub) genotypes (viz. GST-15-204, RGC-1066, RCG-1055, RGC-1038. Ten different doses of gamma rays (viz. $5 \mathrm{kR}, 10 \mathrm{kR}, 15 \mathrm{kR}, 20 \mathrm{kR}, 25 \mathrm{kR}, 30 \mathrm{kR}, 35 \mathrm{kR}, 40 \mathrm{kR} 45 \mathrm{kR}$ and $50 \mathrm{kR}$ ) were applied to. mutagenised the seeds of cluster bean genotypes. The effectiveness and efficiency was determined by accounting lethality and sterility in $\mathbf{M}_{1}$ generation of mutagenized seeds and frequency and spectrum of chlorophyll mutations in $\mathrm{M}_{2}$ generation. Four types of chlorophyll mutants albino, xantha, chlorina and viridis were screened in $\mathrm{M}_{2}$ generation. It has been observed that the frequency of mutations increased with increasing doses of mutagen. Though the highest mutation frequency was noticed in $50 \mathrm{kR}$ dose of gamma rays, the mutagenic effectiveness and efficiency was decreased with increased doses of gamma rays. Thus, the lower doses of mutagen like gamma rays were observed to be more effective and efficient than the higher doses of gamma rays in all four clusterbean genotype.

\section{Introduction}

Clusterbean (Cyamopsis tetragonoloba (L.) Taub.) $(2 \mathrm{n}=14)$ is a member of leguminosae and sub-family papilionaceae. It is an important multipurpose crop specially grown for gum, feed, green fodder, vegetable and green manuring. Clusterbean also known as guar and is a native plant of India, mainly grown in the dry habitats of Rajasthan, Haryana, Gujarat and Punjab. Contributing
$80 \%$ of the world production of this crop is in India, and due to strong demand it is also being introduced into newer areas of semi-arid tracts. The importance of this legume has been highly appreciated as a source of guar gum, which has a multitude of different applications in food products, industrial products and extractive industry.

The significant amount of genetic variation is a most important tool in plant breeding and 
it's a primitive requisite in all crops before laid out the breeding program, it does not preexist. Genetic variation can be created by using various crop improvement methods eg. hybridization, domestication and plant introduction etc. In the clusterbean creation of genetic variability through the recombination of genes by hybridization is very difficult and cumbersome owing to small, delicate flower structures resulting in low percentage of crossed seed setting in the manually hybridized buds. Due to these reasons, Conventional breeding approaches is not relevant way to generate desirable genetic variability

Therefore, mutation breeding can be important tool for enriching genetic variation in the clusterbean and looking at this limitation, efforts will be initiated during the research work to create variability in clusterbean by using the tool of induced mutations.

To create mutation effective mutagens and their doses are prerequisites. Mutagenic effectiveness means the rate of mutations as related to dose while efficiency refers to the mutation rate in relation to biological damage such as seedling injury, pollen sterility and lethality in $\mathrm{M}_{1}$ generation (Nilan et al., 1965).

Mutagenic effectiveness and efficiency gives an idea for mutagen evaluation. Hence these two parameters were used in the present investigation in cluster bean genotypes- GST15-204, RGC-1066, RGC-1055 and RGC1038. The parameters of $\mathrm{M}_{1}$ generation are the best indicator in measuring efficiency of mutagens and helped in comparing the effectiveness and efficiency of physical mutagen gamma rays.

In the present investigation, attempt was made to analyze the mutagenic effectiveness and efficiency of a physical mutagen (gamma rays) in clusterbean genotypes- GST-15-204,
RGC-1066, RGC-1055, RGC-1038by using biological damages like seedling injury, pollen sterility and lethality observed in $M_{1}$ generation in relation with the frequency and spectrum of chlorophyll mutations in $\mathrm{M}_{2}$ generation.

\section{Materials and Methods}

The selected experimental material for the present investigation was clusterbean (Cyamopsis tetragonoloba (L.) Taub.) The experimental seed material of clusterbean genotypes- RGC-1066, RGC-1038, RGC1055, GST-15-204 were collected from RVSKVV, Gwalior and RARI, Durgapura, Jaipur. The Physical Mutagen (gamma-rays) was used for mutation studies.

Healthy, uniform and dry 200 seeds of the clusterbean genotypes were packed in polythene bags and sealed for the Gamma radiation. Electromagnetic, ionizing radiations were applied from Co60 source of irradiation. Gamma radiation was carried out at National botanical research institute, Lucknow. The seed samples were exposed to doses of $5 \mathrm{kR}$, $10 \mathrm{kR}, 15 \mathrm{kR}, 20 \mathrm{kR}, 25 \mathrm{kR}, 30 \mathrm{kR}, 35 \mathrm{kR}, 40 \mathrm{kR}$, $45 \mathrm{kR}, 50 \mathrm{kR}$ of gamma rays.

200 seeds of each treatment along with control (untreated seeds) were sown in research field Individual selected progeny of $\mathrm{M}_{1}$ generation were sown by compact family block design.

\section{In $M_{1}$ generation}

\section{Pollen sterility}

Pollen sterility was determined in 25 randomly selected plants from each treatment. The pollen grains from freshly dehisced anthers were stained with $1 \%$ Acetocarmine. The pollen grains which stained were counted as pollen fertile and partially unstained was considered as pollen sterile. 
Lethality

Data on lethality was expressed in percentage.

\section{In $\mathrm{M}_{2}$ generation}

\section{Chlorophyll mutations}

The chlorophyll mutations were screened and recorded in the field when the seedlings were 7-10 days old. The types of chlorophyll mutations scored like albino, Xantha, chlorina and Viridis. These are classified according to the terminology of (Gustafsson, 1940). The frequency of chlorophyll mutants was calculated according to (Gaul, 1960) i.e. Number of mutants / 100 M2 plants.

\section{Estimation of mutagenic effectiveness and efficiency}

Mutagenic effectiveness and efficiency of different mutagens were calculated according to the formulae suggested by (Konzak et al., 1965). The mutagenic effectiveness can be measured of the frequency of mutations induced by a unit dose of mutagen (kR or time $x$ concentration) while mutagenic efficiency gives an idea of the proportion of mutations in relation to biological damage such as lethality, pollen sterility.

Mutation frequency (MF)

Mutagenic effectiveness $=$

Dose or (Time X Concentration) $=\mathrm{MF} / \mathrm{kR}$ or $\mathrm{MF} / \mathrm{TC}$

Where, $\mathrm{MF}=\%$ of chlorophyll mutations in M2 generation.

$\mathrm{T}=$ Period of treatment with chemical mutagen.

$\mathrm{C}=$ Concentration of chemical mutagens,

$\mathrm{kR}=$ unit of gamma radiation.
Mutation frequency (MF)

Mutagenic efficiency $=$

Biological damage $=\mathrm{MF} / \mathrm{L}, \mathrm{MF} / \mathrm{S}$,

Where,

$\mathrm{L}=\%$ of lethality in $\mathrm{M}_{1}$ generation.

$\mathrm{I}=\%$ of seeding injury in $\mathrm{M}_{1}$ generation.

$\mathrm{S}=\%$ of pollen sterility in $\mathrm{M}_{1}$ generation .

$\mathrm{MI}=\%$ of mitotic abnormalities in $\mathrm{M}_{1}$ generation.

\section{Results and Discussion}

\section{Biological Damages in $\mathrm{M}_{1}$ Generation}

The present study revealed that the pollen sterility and lethality were recorded lower to high with the increasing doses of physical mutagen in all cluster bean genotypes in $\mathrm{M}_{1}$ generation. The biological damages like pollen sterility and lethality were recorded in $\mathrm{M}_{1}$ generation. The sterility was recorded ranged from $5.26 \%$ to $59.09 \%$. The maximum pollen sterility was recorded at $50 \mathrm{kR}$ dose viz. GST-15-204 (59.09\%), RGC-1055 (43.53\%), RGC1066 (40.26\%), RGC-1038(41.76\%) and minimum pollen sterility was recorded at 5 KR viz. GST-15-204(6.63\%), RGC-1055 (7.225\%), RGC-1066 (5.89\%), RGC-1038 (5.26\%). Similarly, higher lethality was recorded at $50 \mathrm{KR}$ viz. GST-15-204 (77\%), RGC-1055 (72\%), RGC1066 (74\%), RGC$1038(71 \%)$ and lower pollen lethality at $5 \mathrm{KR}$ dose viz. GST-15-204 (15\%), RGC-1055 (18\%), RGC1066 (7\%), RGC-1038 (11\%) in all the four genotypes but, pollen sterility and lethality were also varied from one genotype to other genotype. The maximum pollen sterility was found in genotype viz. GST-15$204(59.09 \%)$ and minimum in genotype viz. RGC-1066 (40.26). Similarly, maximum 
lethality was found in genotype viz. RGC1066(74) and minimum in genotype viz. RGC1038 (7\%). Thus, these biological damages were recorded lower at lower doses of gamma rays and higher at higher doses of gamma rays in cluster bean genotypes (Table 1).

Hence, Higher dose of gamma rays might be very useful in clusterbean for producing male sterility during hybridization program of cluster bean.

The increased injury, sterility and lethality with increasing doses of mutagens also reported by several investigators Patil et al.,(2015), Bhosle and Kothekar (2010), S. Velu et al., (2007), Reddy et al., (1991) in cluster bean. The results of present investigations are in conformity with these results. Similar results were also obtained by More and Borkar (2016) in French bean, Monica and Seetharaman (2016) in lablab.

\section{Mutation Frequency in $\mathbf{M}_{2}$ Generation}

Mutation frequency is frequency of chlorophyll mutations calculated on $\mathrm{M}_{2}$ plant basis. In the present investigation, it was recorded that the mutation frequency increased with increasing doses of gamma rays only in two genotypes of clusterbean viz., GST-15-204 \& RGC-1066 but mutation frequency decreased with increasing doses of gamma rays in two other genotypes viz., RGC1055 \& RGC-1038. Chlorophyll mutants were found in almost all the mutagenic doses of gamma rays except some doses viz., 25kR, 35kR \& 45kR (GST-15-204), 20kR (RGC1066 ) and $35 \mathrm{kR}$ (RGC-1038) and $10 \mathrm{kR}$ in (RGC-1055). Chlorophyll mutation was not recorded at $35 \mathrm{kR}$ treatment of gamma rays in all studied genotypes. The highest chlorophyll mutation frequency 1.5 was recorded in $50 \mathrm{KR}$ while the lowest 0.5 recorded in $30 \mathrm{KR}$ treatments. The chlorophyll mutation frequency was increased from $5 \mathrm{kR}(0.75)$ to
$20 \mathrm{kR}$ (1.5) but it decreased in $30 \mathrm{kR}$ but frequency of $50 \mathrm{kR}(0.75)$ was same as $5 \mathrm{kR}$ (0.75) in genotype GST-15-204. The chlorophyll mutation frequency was decreased from $5 \mathrm{kR}$ to $45 \mathrm{kR}$ in two genotype RGC-1055 \& RGC-1038. In the segregating $\mathrm{M}_{2}$ generation, spectrum of chlorophyll mutations indicated the presence of four types of chlorophyll mutants viz., albina, xantha, viridis, chlorina. Viridis and chlorina were observed in $5,10,15,20,25,30,40 \& 50 \mathrm{kR}$ treatments but Albino was observed in only $10 \mathrm{kR} \&$ Xantha was observed in only in 15 and 50kR (plate-1, 2, 3). Chlorina was found in mostly doses. The highest frequency of cholorina mutant was recorded $1.75 \%$ in $5 \mathrm{kR}$ and lowest $20 \mathrm{kR}$ treatments.

Bhosle S.S. and Kothekar V.S. (2010) also recorded that the mutation frequency is increased with increasing doses of gamma rays, EMS and SA in M2 progenies of cluster bean varities GE-36 and HR. Among the gamma rays treatment, the highest mutation frequency was recorded $2.6 \%$ in $15 \mathrm{KR}$ and lowest $1.66 \%$ in $5 \mathrm{KR}$ treatment in the variety GE-36 while it was higher $3.33 \%$ I $15 \mathrm{KR}$ and $1.61 \%$ in $5 \mathrm{KR}$ treatment of gamma rays in the variety HR. Patil et al., (2015) was also observed chlorine mutant in 3040 and $50 \mathrm{kR}$ doses.

\section{Mutagenic Effectiveness}

The mutagenic effectiveness is a measure of factor mutations induced by a unit dose of mutagen. In $\mathrm{M}_{2}$ generation of clusterbean after Gamma rays treatment, the numerical value of effectiveness gradually decreased with increases in the dose of the mutagen in all the genotypes. The range for gamma rays treatment was $5 \mathrm{kR}$ to $50 \mathrm{kR}$. The highest value of mutagenic effectiveness 0.15 was recorded in $5 \mathrm{KR}$ treatment and lowest 0.01 in 50KR treatment in GST-15-204, In RGC-1066 highest value was $0.07(10 \mathrm{kR}) \&$ lowest was 
$0.03(50 \mathrm{kR})$, in RGC-1055 highest value was $0.3(5 \mathrm{kR})$ \& lowest was $0.03(25 \mathrm{kR})$, in RGC1038 highest value was $0.35(5 \mathrm{kR})$ \& lowest was $0.005(45 \mathrm{kR}) .0 .35$ was the highest value of efficiency which was found in genotype RGC-1038 at 5kR dose (Table 2). Thus the lower doses of gamma rays were most effective.

These results were supported by the results obtained in cluster bean by Velu et al., (2007). They reported higher mutagenic effect variety Pusa-Navbahar at lower doses of gamma rays and EMS. However EMS and its doses were found to be more effective mutagen than the gamma rays. Bhosle and Kothekar (2010) also reported reduction in the value of mutagenic effectiveness with the increased doses or concentration of mutagens gamma rays, EMS and SA respectively in the cluster bean varieties GE-36 and HR. SA proved to be more effective than gamma rays and EMS in both the varieties.

The mutagenic effectiveness was also reported by Dube et al., (2011) in cluster bean variety sharada by using variable doses of Gamma rays, EMS and their combination. The mutagenic effectiveness was calculated on the basis of chromosomal aberrations rather than chlorophyll mutation frequency in $\mathbf{M}_{2}$ plants. These results also confirmed results of present investigation.

Table.1 Effect of Gamma rays on biological damages in $\mathrm{M}_{1}$ generation of clusterbean genotype viz. GST-15-204, RGC-1055, RGC-1066, RGC-1038 due to effect of Gamma rays

\begin{tabular}{|c|c|c|c|c|c|c|c|c|c|c|}
\hline Doses & \multicolumn{5}{|c|}{$\%$ pollen sterility $(\mathbf{S})$} & \multicolumn{5}{|c|}{ \% lethality(L) } \\
\hline $\begin{array}{l}\text { kR } \\
\text { doses }\end{array}$ & 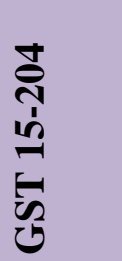 & 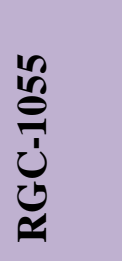 & 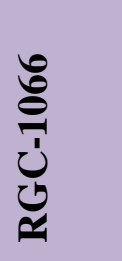 & 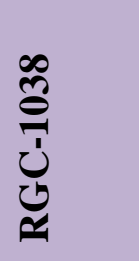 & $\sum_{\Sigma}^{\bar{\varpi}}$ & 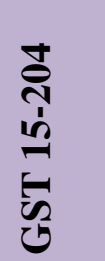 & 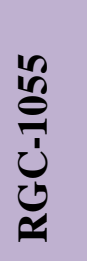 & 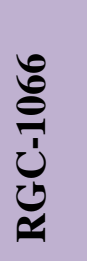 & ֻِ & 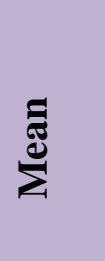 \\
\hline $5 \mathbf{k R}$ & 6.63 & 7.22 & 5.89 & 5.26 & 6.3 & 15 & 18 & 11 & 7 & 12.8 \\
\hline $10 \mathrm{kR}$ & 9.09 & 8.36 & 8.37 & 8.37 & 8.5 & 21 & 20 & 12 & 18 & 17.8 \\
\hline $15 \mathrm{kR}$ & 10.71 & 9.67 & 10.02 & 10.02 & 10.1 & 35 & 25 & 25 & 23 & 27.0 \\
\hline $20 \mathrm{kR}$ & 12.5 & 13.61 & 11.48 & 11.48 & 12.3 & 42 & 38 & 32 & 36 & 37.0 \\
\hline $25 \mathrm{kR}$ & 15.2 & 12.43 & 14.26 & 14.26 & 14.0 & 50 & 44 & 39 & 42 & 43.8 \\
\hline 30KR & 17.64 & 15.11 & 17.21 & 17.21 & 16.8 & 57 & 55 & 42 & 53 & 51.8 \\
\hline $35 \mathrm{kR}$ & 23.07 & 19.5 & 20.13 & 20.13 & 20.7 & 63 & 59 & 45 & 57 & 56.0 \\
\hline $40 \mathrm{kR}$ & 30.76 & 26.36 & 24.07 & 24.07 & 26.3 & 69 & 66 & 57 & 64 & 64.0 \\
\hline $45 \mathrm{kR}$ & 40.9 & 35.65 & 33.03 & 33.03 & 35.7 & 74 & 71 & 61 & 68 & 68.5 \\
\hline $50 \mathrm{kR}$ & 59.09 & 43.53 & 40.26 & 41.76 & 46.2 & 77 & 72 & 74 & 71 & 73.5 \\
\hline
\end{tabular}


Table.2 Effectiveness of gamma rays in $\mathrm{M}_{2}$ generation of clusterbean genotype Viz., GST-15204, RGC-1055, RGC-1066, RGC-1038

\begin{tabular}{|c|c|c|c|c|c|c|c|}
\hline \multirow{2}{*}{$\begin{array}{l}\text { Doses } \\
\text { kR doses }\end{array}$} & \multicolumn{5}{|c|}{ Frequency of \% chlorophyll mutation (MF) } & \multicolumn{2}{|c|}{$\begin{array}{l}\text { Effectiveness } \\
\text { (MF/doses) }\end{array}$} \\
\hline & 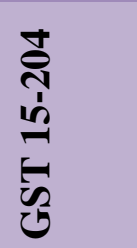 & 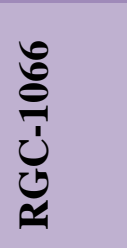 & 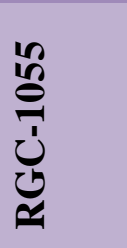 & ֻِ & 苋 & 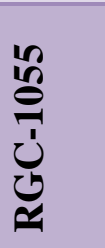 & 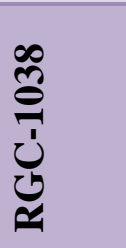 \\
\hline $5 \mathbf{k R}$ & 0.75 & 0 & 1.5 & 1.75 & 0 & 0.3 & 0.35 \\
\hline 10kR & 1.25 & 0.75 & 0 & 0.5 & 0.06 & 0 & 0.05 \\
\hline 15kR & 1 & 1 & 0 & 0.75 & 0.06 & 0 & 0.05 \\
\hline $20 \mathrm{kR}$ & 1.5 & 0 & 0 & 0.75 & 0 & 0 & 0.035 \\
\hline 25kR & 0 & 0.25 & 0.75 & 1 & 0.01 & 0.03 & 0.04 \\
\hline 30KR & 0 & 1.25 & 0 & 0 & 0.04 & 0 & 0 \\
\hline 35kR & 0 & 0 & 0 & 0 & 0 & 0 & 0 \\
\hline 40kR & 0 & 0 & 0 & 0 & 0 & 0 & 0 \\
\hline 45kR & 0.75 & 0 & 0 & 0.25 & 0 & 0 & 0.005 \\
\hline $50 \mathrm{kR}$ & 0.75 & 1.5 & 0 & 0 & 0.03 & 0 & 0 \\
\hline
\end{tabular}

Table.3 Mutagenic efficiency of Gamma rays in $\mathrm{M}_{2}$ generation of clusterbean genotype Viz., GST-15-204

\begin{tabular}{|c|c|c|c|c|c|}
\hline Dose & $\begin{array}{c}\text { \%Chlorophyll } \\
\text { Mutation (MF) }\end{array}$ & $\begin{array}{c}\text { \% Lethality } \\
(\mathbf{L})\end{array}$ & $\begin{array}{c}\text { Efficiency } \\
\text { (MF/L) }\end{array}$ & $\begin{array}{c}\text { Pollen } \\
\text { Sterility } \\
(\mathbf{S})\end{array}$ & $\begin{array}{c}\text { Efficiency } \\
\text { (MF/S) }\end{array}$ \\
\hline $\mathbf{5 k R}$ & 0.75 & 15 & 0.05 & 5.26 & 0.14 \\
\hline $\mathbf{1 0 k R}$ & 1.25 & 21 & 0.05 & 9.09 & 0.13 \\
\hline $\mathbf{1 5 k R}$ & 1 & 35 & 0.02 & 10.71 & 0.09 \\
\hline $\mathbf{2 0 k R}$ & 1.5 & 42 & 0.03 & 12.5 & 0.12 \\
\hline $\mathbf{2 5 k R}$ & 0 & 50 & 0 & 15.2 & 0 \\
\hline $\mathbf{3 0 K R}$ & 0 & 57 & 0 & 17.64 & 0 \\
\hline $\mathbf{3 5 k R}$ & 0 & 63 & 0 & 23.07 & 0 \\
\hline $\mathbf{4 5 k R}$ & 0 & 74 & 0 & 40.9 & 0 \\
\hline $\mathbf{5 0 k R}$ & 0.75 & 76 & 0.009 & 59.09 & 0.01 \\
\hline
\end{tabular}


Table.4 Mutagenic efficiency of Gamma rays in $\mathrm{M}_{2}$ generation of clusterbean genotype Viz., RCG-1066

\begin{tabular}{|c|c|c|c|c|c|}
\hline Dose & $\begin{array}{c}\text { \% Chlorophyll } \\
\text { Mutation } \\
\text { (MF) }\end{array}$ & $\begin{array}{c}\text { \% } \\
\text { Lethality } \\
(\mathbf{L})\end{array}$ & $\begin{array}{c}\text { Efficiency } \\
\text { (MF/L) }\end{array}$ & $\begin{array}{c}\text { Pollen } \\
\text { Sterility } \\
(\mathbf{S})\end{array}$ & $\begin{array}{c}\text { Efficiency } \\
\text { (MF/S) }\end{array}$ \\
\hline $\mathbf{1 0 k R}$ & 0.75 & 12 & 0.06 & 8.37 & 0.08 \\
\hline $\mathbf{1 5 k R}$ & 1 & 25 & 0.04 & 10.02 & 0.09 \\
\hline $\mathbf{2 0 k R}$ & 0 & 32 & 0 & 11.48 & 0 \\
\hline $\mathbf{2 5 k R}$ & 0.25 & 39 & 0.0064 & 14.26 & 0.01 \\
\hline $\mathbf{3 0 k R}$ & 1.25 & 42 & 0.0297 & 17.21 & 0.07 \\
\hline $\mathbf{5 0 k R}$ & 1.5 & 61 & 0.02 & 33.03 & 0.04 \\
\hline
\end{tabular}

Table.5 The Mutagenic efficiency of Gamma rays in $\mathrm{M}_{2}$ generation of clusterbean genotype Viz., RGC-1055

\begin{tabular}{|c|c|c|c|c|c|}
\hline Dose & $\begin{array}{c}\text { \% Chlorophyll } \\
\text { Mutation } \\
(\mathbf{M F})\end{array}$ & $\begin{array}{c}\text { \% } \\
\text { Lethality } \\
(\mathbf{L})\end{array}$ & $\begin{array}{c}\text { Efficiency } \\
\mathbf{( M F / L )}\end{array}$ & $\begin{array}{c}\text { Pollen } \\
\text { Sterility } \\
\mathbf{( S )}\end{array}$ & $\begin{array}{c}\text { Efficiency } \\
\mathbf{( M F / S})\end{array}$ \\
\hline $\mathbf{5 k R}$ & 1.5 & 18 & 0.08 & 7.22 & 0.20 \\
\hline $\mathbf{1 0 k R}$ & 0 & 20 & 0 & 8.36 & 0 \\
\hline $\mathbf{2 0 k R}$ & 0 & 38 & 0 & 13.61 & 0 \\
\hline $\mathbf{2 5 k R}$ & 0.75 & 44 & 0.01 & 12.43 & 0.06 \\
\hline
\end{tabular}

Table.6 The mutagenic efficiency of Gamma rays in $\mathrm{M}_{2}$ generation of clusterbean genotype Viz., RGC1038

\begin{tabular}{|c|c|c|c|c|c|}
\hline Dose & $\begin{array}{c}\text { \% Chlorophyll } \\
\text { Mutation } \\
\text { (MF) }\end{array}$ & $\begin{array}{c}\text { \% } \\
\text { Lethality } \\
(\mathbf{L})\end{array}$ & $\begin{array}{c}\text { Efficiency } \\
\text { (MF/L) }\end{array}$ & $\begin{array}{c}\text { Pollen } \\
\text { Sterility } \\
(\mathbf{S})\end{array}$ & $\begin{array}{c}\text { Efficiency } \\
\text { (MF/S) }\end{array}$ \\
\hline $\mathbf{5 k R}$ & 1.75 & 11 & 0.15 & 5.89 & 0.29 \\
\hline $\mathbf{1 0 k R}$ & 0.5 & 18 & 0.02 & 8.37 & 0.05 \\
\hline $\mathbf{1 5 k R}$ & 0.75 & 23 & 0.03 & 10.02 & 0.07 \\
\hline $\mathbf{2 0 k R}$ & 0.75 & 36 & 0.02 & 11.48 & 0.06 \\
\hline $\mathbf{2 5 k R}$ & 1 & 42 & 0.02 & 14.26 & 0.07 \\
\hline $\mathbf{3 5 k R}$ & 0 & 57 & 0 & 20.13 & 0 \\
\hline $\mathbf{4 5 k R}$ & 0.25 & 69 & 0.003 & 33.03 & 0.007 \\
\hline
\end{tabular}


Plate.1 Shows chlorophyll mutants plant -Xantha (completely yellow)

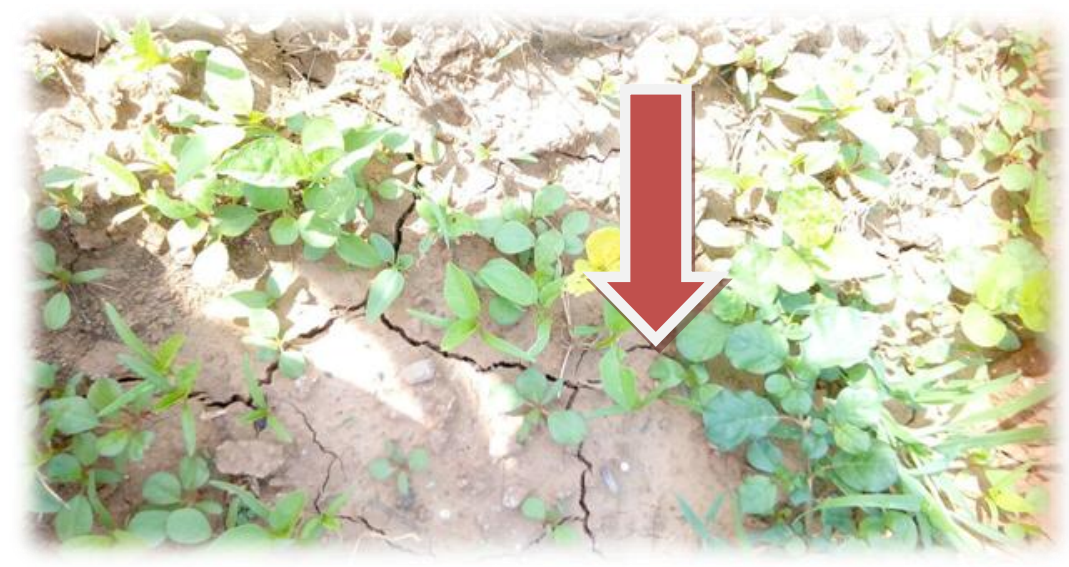

Plate.2 Shows chlorophyll mutants plant -viridis (light green)

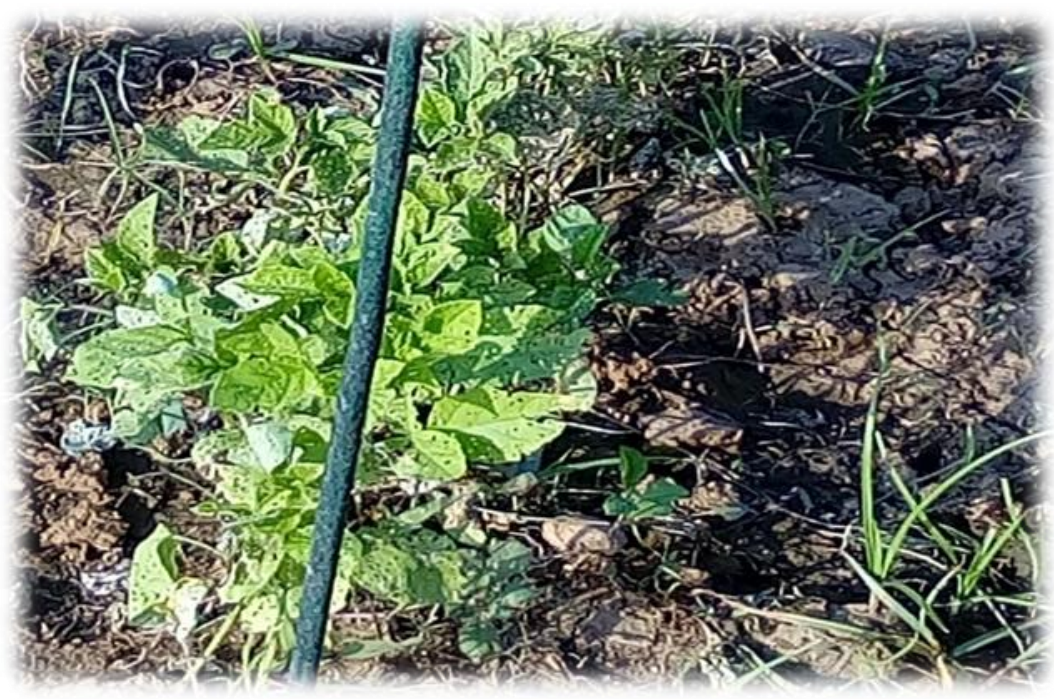

Plate.3 Shows chlorophyll mutants plant - Chlorina (pale green)

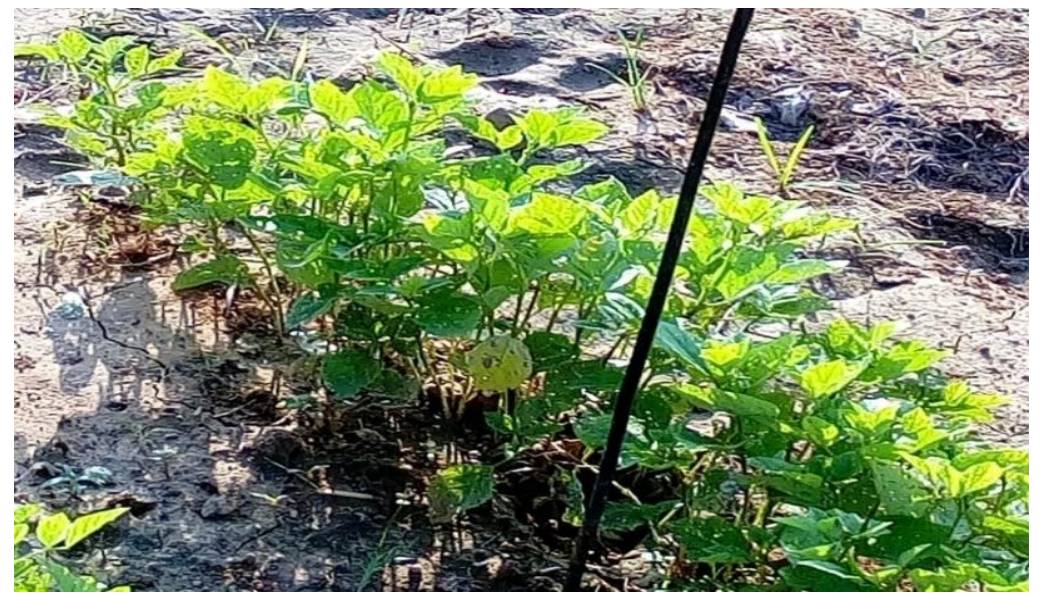




\section{Mutagenic efficiency}

The mutagenic efficiency is the ratio of chlorophyll mutations induced in the $\mathrm{M}_{2}$ generation to the various biological damages induced in $\mathrm{M}_{1}$ generation such as lethality and pollen sterility.

\section{Efficiency in relation to lethality}

In the present study, the mutagenic efficiency decreased with the increasing doses of gamma rays with respect to lethality (L). Highest value of mutagenic efficiency was recorded 0.05 (GST-15-204), 0.08 (RGC-1055), 0.15 (RGC-1038) \& 0.06 (RGC-1066) at 5KR, 10kR and lowest 0.009 (GST-15-204), 0.02 (RGC-1066), $\quad 0.01$ (RGC-1055) \& 0.003 (RGC-1038) at 50, $25 \& 45 \mathrm{kR}$ doses of mutagen.

\section{Efficiency in relation to Pollen sterility}

The observations in respect to efficiency with reference to pollen sterility demonstrated a doses dependent enhancement in majority of the mutagenic treatments in M2 generation of clusterbean genotype. The value of efficiency decreased as there were increases in doses of Gamma rays treatments. It was ranged from 0.01 to 0.29 . Highest value of mutagenic efficiency was recorded 0.14 (GST-15-204), 0.20 (RGC-1055), 0.15 (RGC-1038) \& 0.29 (RGC-1066) at 5KR, 10kR and lowest 0.01 (GST-15-204), 0.04 (RGC-1066), 0.06 (RGC1055) \& RGC-1038(0.05) at 50, $25 \& 45 \mathrm{Kr}$ doses of mutagen.

On the basis of mean values, the highest mutagenic efficiency was recorded 0.0610 in relation to pollen sterility and lowest 0.0249 in relation to lethality (Table 3-6).

Similar results were also reported by S. Velu et al., (2007) in cluster bean variety PusaNavbahar and K. G. Dube et al., (2011) in cluster bean variety Sharada. They proved that lower doses of gamma rays were more efficient than the higher doses. These results were also supported by Manrique et al., (1998) in french bean, M. Khan and Tyagi (2010) in Soybean, S. K. Sharma et al., (2005) in Urd bean, S. K. Sharma and B. Sharma (1979) in Lentil. They concluded that mutagenic efficiency was higher at lower doses of mutagens. These results are in agreement with the results of present investigation

From the present investigation, it was concluded that mutagenic effectiveness and mutagenic efficiency were highest at lower dose of gamma rays in the all clusterbean genotypes the chlorophyll frequency increased with the increasing dose of gamma rays and it was maximum at higher doses and minimum at lower doses of gamma rays. The increased mutagenic dose causes the decrease in the mutagenic effectiveness at higher doses. The mutagenic efficiency was higher at lower doses due to the increased sterility and lethality with increasing doses of gamma rays. Thus, lower doses gamma rays is effective and efficient mutagen in cluster bean which may create genetic variability useful in crop improvement.

\section{Acknowledgement}

The authors are thankful to Dr. Arvind jain, Scientist, National Botanical Research Institute., Lucknow, for providing necessary facility for source of gamma radiation.

\section{References}

Bhosale Sunita S. and V. S. Kothekar (2010). Mutagenic efficiency and effectiveness in clusterbean (Cyamopsis tetragonoloba (L.) Taub), Journal of Phytology, 2(6), 21-27. 
Dube K.G., A.S. Bajaj, and Gawande A. M. (2011). Mutagenic efficiency and effectiveness of gamma rays and EMS in (Cyamopsis tetragonoloba (L.) Var. Sharada, Asiatic Journal of Biotechnology resources, 2(04), 436440.

Gaul, H. (1960). Critical analysis of the methods for determining the mutation frequency after seed treated with mutagens. Genet. Agr., 12: 297-318.

Gustaffason, A. (1940). The mutation system of the chlorophyll apparatus. Lud. Univ. Arasks, N. P. Adv. 36: 1-40.

Konzak C.F., Nilan R.N. Wagner J and Faster R. J. (1965). Efficient chemical mutagenesis in "The use of induced mutation in plant breeding", Radiation Botany, 5, 49-70

Monica, S. and N. Seetharaman (2016) Mutagenic effectiveness and efficiency of Gamma rays and EMS in Lablab purpureus (L.) Sweet var. typicus. Int. J. Adv. Multidiscip. Res. (2016). 3(11): 76-81

More, A.D. and A.T. Borkar. (2016). Mutagenic Effectiveness and Efficiency of Gamma Rays and EMS in Phaseolus vulgaris L. Int.J.Curr.Microbiol.App. Sci., 5(10): 544-554

Patil B. M. and Rane G.M. (2015). Studies on Mutagenic Effectiveness and Mutagenic Efficiency of Gamma Rays in Cluster bean (Cyamopsis tetragonoloba (L) Taub) Var. NCB-12. IOSR-JAVS., PP 13-19.

Reddy D. S., Pampathy K., Suryanarayana V., Kumar P.V. (1991). Mutagenic efficiency and effectiveness of gamma rays, EMS and $\mathrm{HZ}$ in cluster bean (Cyamopsis tetragonoloba (L.) Taub), Andhra Agricultural Journal, 38 (1), 12 -14 .

Sharma S.K., Sharma B. (1979). Mutagenic effectiveness and efficiency of Gamma Rays and N- Nitroso - N - Methyl Urea in Lentil, Indian Journal of Genetics and Plant Breeding, 39 (3), 516-520.

Velu S., Mullainathan L. et.al. (2007). Effectiveness and efficiency of gamma rays and EMS on cluster bean (Cyamopsis tetragonoloba (L.) Taub), Crop Research, 34 (1, 2 and 3), 249251.

\section{How to cite this article:}

Jaya Rathore, A.K. Singh and Chauhan, S.V.S. 2019. Effectiveness and Efficiency of Different Doses of Physical Mutagen ( $\gamma$ - rays) in Clusterbean [Cyamopsis tetragonoloba (L.) Taub.] Genotypes. Int.J.Curr.Microbiol.App.Sci. 8(07): 484-493. doi: https://doi.org/10.20546/ijcmas.2019.807.059 